\title{
Relationships between Mechanical Properties of Polymer Gels and Polymer Volume Fractions at Preparation and at Interested State
}

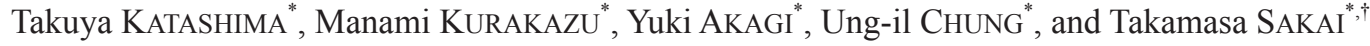 \\ "Department of Bioengineering, School of Engineering, The University of Tokyo, \\ 7-3-1 Hongo, Bunkyo-ku, Tokyo 113-8656, Japan
}

\begin{abstract}
We investigate the effects of polymer volume fraction on the mechanical properties of polymer gels by varying the volume fraction of network at preparation $\left(\varphi_{0}\right)$ and at interested state $\left(\varphi_{\mathrm{m}}\right)$. Furthermore, we investigate the effect of $\varphi_{0}$ on the degree of the equilibrium swelling. We employ the Tetra-PEG gels with precisely tuning network strand length and the polymer volume fraction at preparation $\left(\varphi_{0}\right)$ as a model system. The $\varphi_{0}$-dependence of the elastic modulus is almost proportional to $\varphi_{0} / N$, which corresponds to the prediction of the classical rubber elasticity theory. The $\varphi_{\mathrm{m}}-$ dependence of the elastic modulus exhibits the crossover at $\varphi^{*}$. The dependence in semi-dilute region is stronger than that in dilute regions. The $\phi_{0}$-dependences of the elastic modulus and the polymer volume fraction at the equilibrium swollen state also exhibit the crossover at $\varphi^{*}$. The dependences in semi-dilute region are weaker than those in dilute regions. The Obukhov model successfully describes these dependences by considering the excluded volume effect. On the other hand, the familiar $C^{*}$ theorem fails to explain the experimental results.
\end{abstract}

Key Words: Hydrogel / Elastic modulus / Polymer volume fraction / Excluded volume effect / Tetra-PEG gel

\section{高分子ゲルにおける調製時および 測定時高分子体積分率と力学特性の関係}

\author{
片島 拓弥 ${ }^{*}$, 倉員 麻奈実 ${ }^{*}$, 赤木 友紀 ${ }^{*}$, 鄭 雄一 ${ }^{*}$, 酒井 崇匡 ${ }^{*}+\dagger$
}

(原稿受理：2013 年 12 月 4 日)

\section{1. はじめに}

高分子ゲルは高分子鎖が架橋により 3 次元的網目を形成 し, 溶媒を保持した物質である。溶媒成分の弾性への直接 的な寄与は極めて小さいために, その力学特性は高分子網 目の体積分率に強く依存する. よって, ゲルの本質を理解 するためには, 高分子体積分率が力学特性にどのように影 響を及ぼすかを定量的に理解する必要がある。

ゲルの弾性率は測定時 $\left(\varphi_{\mathrm{m}}\right)$ とゲル調製時 $\left(\varphi_{0}\right)$ の 2 つの体 積分率に依存する。このことは, 等しい有効網目鎖密度や架 橋点間分子量, $\varphi_{\mathrm{m}}$ を持つが, $\varphi_{0}$ の異なる 2 種類のゲルが異 なる弾性率を持つという実験結果より明らかである。この現 象は古くから知られており, Floryらにより理論的な取り扱 いがなされてきた。古典的なゴム弾性理論では, ゲルの膨潤・ 脱膨潤により架橋点がアフィン変形し, 全ての濃度領域にお いて網目鎖がランダムコイルという2つの仮定の下, 弾性 率を $\varphi_{0}, \varphi_{\mathrm{m}}$ および架橋点間重合度 $(N)$ の関数として予測して

* 東京大学大学院工学系研究科 東京都文京区本郷 7-3-1

$\dagger$ To whom correspondence should be addressed

E-mail: sakai@tetrapod.t.u-tokyo.ac.jp (T.S.), Tel: +81-3-5841-1899
いる. ${ }^{1,2)}$ Obukhov らは排除体積が網目鎖の次元に及ぼす効果 を考慮し, 古典的ゴム弾性理論を修正したモデルを提案し た. 排除体積効果は $\varphi_{0}$ や $\varphi_{\mathrm{m}}$ の濃度領域によって異なってく る。彼らはこの排除体積効果により, 弾性率の $\varphi_{0} や \varphi_{\mathrm{m}}$ 依存 性が大きく影響されることを示した. ${ }^{3)}$ 一方で実験的には，天 然ゴムやポリブタジエンゴムなどを用いて研究がなされて きた. ${ }^{4,5}$ J.E.Mark らによって単分散の両末端官能性高分子鎖 を多分岐架橋剤で架橋する end-linking 法を用いたモデルネッ トワークが開発されると ${ }^{6,7)}$, これらを用いた研究が行われ 多くの知見が得られてきた ${ }^{8-10)}$ しかし, これらの研究の多く は調製時の濃度が比較的高い濃度で行われており，高分子 網目内に多くの絡み合いが存在し, 構造パラメータと物性 の関係の精密な理解を妨げていた

ゲルの物理特性を定量的に理解する上で, 網目構造に絡 み合いや未反応性末端などの不均一性が存在しない「理想 網目鎖」を用いた実験は必要不可欠である。近年, 我々は 理想網目に近い構造を有する Tetra-PEG ゲルの作製に成功し た. ${ }^{11-13)}$ Tetra-PEG ゲルは 2 種類の相互連結可能な 4 分岐ポリ エチレングリコール $(\mathrm{PEG})$ 同士の $\mathrm{AB}$ 型クロスリンクカップ リングによって形成される。これまでの先行研究から, 網 目構造の空間的な不均一性や結合不均一性が従来のゲルと 比べて極めて少ないことがわかった. ${ }^{14-16)}$ 微小変形領域及び 
引裂試験から, 網目構造内に絡み合いがほぼなく, 弾性に 有効な連結点が化学架橋によってのみ形成されていること

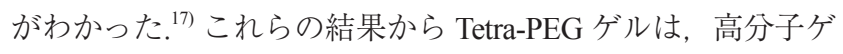
ルの構造と物理特性の関係を定量的に議論するためのモデ ル網目として最適であると考えられる。

本稿では Tetra-PEG ゲルを用いて, 高分子ゲルの膨潤・脱 膨潤を含めた高分子体積分率と力学特性の関係について調 べた研究について紹介する. ${ }^{18)}$

\section{2. 実験}

\subsection{Tetra-PEG ゲルの作製}

Tetra-amine-terminated PEG (TetraPEG-NH $\mathrm{NH}_{2}$ と tetra-OSuterminated PEG (TetraPEG-OSu) は日油株式会社から購入した. プレポリマーの分子量 $\left(M_{\mathrm{pre}}\right)$ は等しいものを使用した $\left(M_{\mathrm{pre}}=\right.$ $10 \mathrm{k}, 20 \mathrm{k} \mathrm{g} / \mathrm{mol})$. Tetra-PEG-NH $\mathrm{N}_{2}$. Tetra-PEG-OSu をそれぞれ

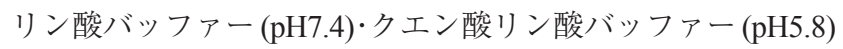
に $60-120 \mathrm{~g} / \mathrm{L}$ になるように溶解した。 このときの各々の調 製時高分子体積分率 $\left(\varphi_{0}\right)$ は $0.051-0.096$ である（PEGの密 度は $1.129 \mathrm{~g} / \mathrm{cm}^{3}$ として計算した). 反応速度を制御するため にバッファーのイオン強度を低濃度側 $\left(\varphi_{0}=0.051\right.$ - 0.066) で は $50 \mathrm{mM}$ に, 高濃度側 $\left(\varphi_{0}=0.081-0.096\right)$ では $100 \mathrm{mM}$ に調 製した。二液を混合し, 混合溶液をモールドの中に注入し, 反応終了まで 12 時間ほど静置した.

\section{2 制御された膨潤度を有するゲルの作製}

不純物を除去するため $\varphi_{0}=0.051,0.096$ のゲル試験片（重 量 $w_{0}$ ）を脱イオン水に浸漬させ， 1 日静置した。異なる $\varphi_{\mathrm{m}}$ を持つゲルを得るため, 平衡膨潤状態のゲルを空気中にて静 置時間を変えつつ保持した. 部分的に乾燥させた試験片（重 量： $w_{\mathrm{s}}$ ）をマイクロチューブ内にて平衡に達するまで 2 日間 静置した，以下の式を用いて， $w_{0}, w_{\mathrm{s}}$ から $\varphi_{\mathrm{m}}$ を計算した.

$$
\phi_{\mathrm{m}}=\frac{c}{\rho-1+w_{\mathrm{s}} / w_{0}(1+c)}
$$

ここで $\rho_{\mathrm{PEG}}$ は PEG の質量密度 $\left(=1.129 \mathrm{~g} / \mathrm{cm}^{3}\right), \quad c$ は調製時高 分子濃度を示す。

\section{3 一軸延伸試験}

一軸延伸試験は Autograph AG-X plus (SHIMADZU co.) を用 いて行った。試験片は短冊状(長さ : $50 \mathrm{~mm}$, 厚さ : $2.0 \mathrm{~mm}$, 幅: $5.0 \mathrm{~mm})$ のものを用いた. クロスヘッドの速度は $1.0 \mathrm{~mm} / \mathrm{sec}$ で実験を行った。この歪速度で一定歪を印加した後, 静置 した際に応力の緩和は見られず, 得られた応力は平衡応力 であることを確認している.

\section{3. 理論的背景}

\section{1 高分子体積分率と弾性率の関係について}

本章では, 膨潤・脱膨潤状態におけるゲルの高分子体積 分率と弾性率の関係についての理論を紹介する。記述の多 くは文献 10 に則っている，ゲルの弾性自由エネルギー $\left(F_{\mathrm{el}}\right)$ は次のように表せる.

$$
\frac{F_{\mathrm{el}}}{a^{3}} \cong \frac{E}{3}=v_{\mathrm{el}} F_{\mathrm{el}}^{0}=\frac{\phi}{a^{3} N} F_{\mathrm{el}}^{0}
$$

ここで $a^{3}, \varphi, E, v_{\mathrm{el}}, F_{\mathrm{el}}{ }^{0}$ はそれぞれモノマーの体積, 高分子体 積分率, Young 率, 有効網目鎖密度, 一網目鎖あたりの弾性

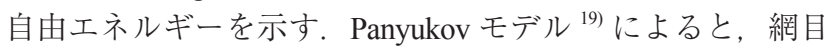
鎖のエネルギーが Hooke の法則に従うので, $F_{\mathrm{el}}{ }^{0}$ は次のよう に表せる。

$$
F_{\text {el }}^{0} \cong\left(\frac{\lambda R_{0}}{R_{\text {ref }}}\right)^{2} k_{\mathrm{B}} T
$$

ここで $k_{\mathrm{B}}, T, R_{0}, R_{\mathrm{ref},} \lambda$ は Boltzmann 定数, 絶対温度, 調製時 $\left(\varphi_{0}\right)$ の網目鎖（重合度 $\left.N\right)$ の平均二乗末端間距離, 測定時濃 度 $\left(\varphi_{\mathrm{m}}\right)$ の溶液における高分子鎖（重合度 $\left.N\right)$ の末端間距離, 網目鎖の膨潤・脱膨潤による一軸変化率を示す. Obukhov モ デルは膨潤・脱膨潤に伴う体積変化により架橋点がアフィ ン変形することを仮定しており， $\lambda=\left(\varphi_{0} / \varphi_{\mathrm{m}}\right)^{1 / 3}$ と表せる.ゲ ルを調製時濃度において測定する場合 $\left(\varphi_{\mathrm{m}}=\varphi_{0}\right), \quad(3)$ 式は $k_{\mathrm{B}} T$ となるため, ゲルの弾性自由エネルギーは式 (4)のようにな り，古典的なゴム弾性理論と一致する.

$$
\frac{F_{\mathrm{el}}}{a^{3}} \cong \frac{E}{3}=v_{\mathrm{el}} k_{\mathrm{B}} T=\frac{\phi}{a^{3} N} k_{\mathrm{B}} T
$$

高分子鎖の末端間距離 $(R)$ の $\varphi$ 依存性はその濃度域により次 のように分類される。（1) 良溶媒の希薄溶液では $R$ は $\varphi$ に依 存せず，孤立鎖の $R$ に等しい.

$$
R \cong a N^{v} \quad\left(\varphi<\varphi^{*}\right)
$$

$\varphi^{*}$ 及び $v$ は重なり合い濃度, 排除体積指数を示す。(2) 準希 薄溶液では $\varphi$ の増加に伴い, 排除体積効果による遮蔽が起 こる，スケーリング理論により，Rの $\varphi$ 依存性は次のように 予測されている. ${ }^{20)}$

$$
R \cong a N^{v}\left(\frac{\phi}{\phi^{*}}\right)^{\frac{2 v-1}{2(1-3 v)}} \quad\left(\varphi^{*}<\varphi<\varphi^{* *}\right)
$$

(3) 排除体積効果が完全に遮蔽される濃厚領域 $\left(\varphi>\varphi^{* *}\right)$ にお いては, $R$ は非摂動状態に等しい.

$$
R \cong a N^{1 / 2} \quad\left(\varphi>\varphi^{* *}\right)
$$

各濃度域における $R$ の $\varphi$ 依存性の違いから, 測定時 $(\varphi=$ $\left.\varphi_{\mathrm{m}}\right)$ の弾性率 $E_{\mathrm{m}}$ は $\varphi_{0}$ と $\varphi_{\mathrm{m}}$ の関数として次のように記述出来 る。本稿で問題とする濃度域がすべて $\varphi^{* * *}$ 以下なので, そ の領域のみに限って議論を行う。式 (2), (5) (6)より, 以下の ように予測される.

$$
\begin{array}{ll}
E_{\mathrm{m}} \sim N^{-1} \phi_{0}^{\frac{2}{3}} \phi_{\mathrm{m}}^{\frac{1}{3}} & \left(\varphi_{0}<\varphi^{*} \text { and } \varphi_{\mathrm{m}}<\varphi^{*}\right) \\
E_{\mathrm{m}} \sim N^{-1} \phi_{0}^{\frac{2}{3}} \phi_{\mathrm{m}}^{\frac{9 v-4}{9 v-3}} & \left(\varphi_{0}<\varphi^{*} \text { and } \varphi^{*}<\varphi_{\mathrm{m}}<\varphi^{* *}\right) \\
E_{\mathrm{m}} \sim N^{-1} \phi_{0}^{\frac{1}{9 v-3}} \phi_{\mathrm{m}}^{\frac{1}{3}} & \left(\varphi^{*}<\varphi_{0}<\varphi^{* *} \text { and } \varphi_{\mathrm{m}}<\varphi^{*}\right) \\
E_{\mathrm{m}} \sim N^{-1} \phi_{0}^{\frac{1}{9 v-3}} \phi_{\mathrm{m}}^{\frac{9 v-4}{9 v-3}} & \left(\varphi^{*}<\varphi_{0}<\varphi^{* *} \text { and } \varphi^{*}<\varphi_{\mathrm{m}}<\varphi^{* *}\right)
\end{array}
$$




\section{2 平衡膨潤状態について}

平衡膨潤時におけるゲルの高分子体積分率 $\left(\varphi_{\mathrm{s}}\right)$ と弾性 率 $\left(E_{\mathrm{s}}\right)$ の関係は Flory-Rehnerの仮定から導かれる. ${ }^{1,21)}$ FloryRehnerの仮定では, ゲルの系全体の自由エネルギーは混合 の自由エネルギー $\left(F_{\text {mix }}\right)$ と弾性の自由エネルギー $\left(F_{\mathrm{el}}\right)$ に分離

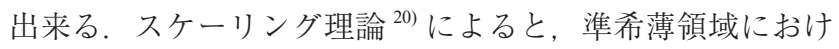
る混合の自由エネルギーは次のように表せる。

$$
\frac{F_{\text {mix }}}{k_{\mathrm{B}} T} \approx \frac{\pi a^{3}}{k_{\mathrm{B}} T} \sim \phi^{\frac{3 v}{3 v-1}}
$$

ここで $\pi$ は浸透圧を示す。平衡澎潤状態は系全体の自由工 ネルギーが最小になるように決まる $\left({ }^{2} F_{\text {mix }} / \partial \phi=F_{a} / \partial \phi\right)$. そのため, 式 (8a) と $(8 \mathrm{c})$ を用いて $\varphi_{\mathrm{s}}$ と $\varphi_{0}$ の関係は次のように表せる。

$$
\begin{array}{ll}
\phi_{\mathrm{s}} \sim E_{0}^{\frac{9 v-3}{6 v+1}} \phi_{0}^{\frac{1-3 v}{6 v+1}} & \left(\varphi_{0}<\varphi^{*}\right) \\
\phi_{\mathrm{s}} \sim E_{0}^{\frac{9 v-3}{6 v+1}} \phi_{0}^{\frac{4-9 v}{6 v+1}} & \left(\varphi^{*}<\varphi_{0}<\varphi^{* *}\right)
\end{array}
$$

さらに $E_{\mathrm{s}}$ と $\varphi_{0}$ の関係は

$$
\begin{array}{ll}
E_{\mathrm{s}} \sim E_{0}^{\frac{9 v}{6 v+1}} \phi_{0}^{\frac{-3 v}{6 v+1}} & \left(\varphi_{0}<\varphi^{*}\right) \\
E_{\mathrm{s}} \sim E_{0}^{\frac{9 v}{6 v+1}} \phi_{0}^{\frac{3 v(4-9 v)}{(3 v-1)(6 v+1)}} & \left(\varphi^{*}<\varphi_{0}<\varphi^{* *}\right)
\end{array}
$$

と書ける。式 (10), (11)より $E_{\mathrm{s}}$ の $\varphi_{\mathrm{s}}$ 依存性は濃度領域に依ら ず，式(12)のようになる.

$$
E_{\mathrm{s}} \sim \phi_{\mathrm{s}}^{\frac{3 v}{3 v-1}}
$$

\section{4. 結果と考察}

\section{1 弾性率の $\varphi_{0}$ 依存性について}

本章では調製状態のゲルを膨潤・脱膨潤せず，そのまま 測定をした時の弾性率について議論をする。弾性率の議論 に入る前に, Tetra-PEG ゲルの末端反応率 $(p)$ から架橋点間 分子量 $(N)$ を見積もり, その $\varphi_{0}$ 依存性について議論をする. Fig. 1 に赤外分光法により求めた $p$ の $\varphi_{0}$ 依存性を示す. 反応 率算出の詳細は先行論文に掲載があるので, 本稿では割愛 する. ${ }^{14)} p$ は $\varphi_{0}$ に依らず, およそ $0.9-0.95$ で一定值を取った.

得られた $p$ を用い, 以下の式から架橋点間分子量 $\left(N_{\mathrm{p}}\right)$ を 見積もった。

$$
\rho\left(\phi_{0}-\phi_{\mathrm{sol}}\right)=m_{\mathrm{PEG}} N_{\mathrm{p}} v_{\mathrm{el}}
$$

ここで $\rho$ と $\mathrm{m}_{\mathrm{PEG}}$ はそれぞれ $\mathrm{PEG}$ の密度, モノマー分子量を 示す. $v_{\mathrm{el}}$ と $\varphi_{\mathrm{sol}}$ は弾性に有効な網目鎖密度とゾル分率を示し, それぞれ樹状構造理論を用いて $p$ から見積もった. ${ }^{14,22)}$ 得られ た $N_{\mathrm{p}}$ の $\varphi_{0}$ 依存性を Fig. 2 に示す。 $N_{\mathrm{p}}$ は $\varphi_{0}$ に依らずほぼ一 定值を取り，プレポリマー分子量から予測される架橋点間 重合度（プレポリマー分子量からは $10 \mathrm{k}, 20 \mathrm{k}$ Tetra-PEG ゲル で $N=113,227$ と予測される）に近い值を取った。これは $p$ が $\varphi_{0}$ に依らず，高い反応率を示していることを反映してい る.
Fig. 3 (a)に 10 k, 20 k Tetra-PEG ゲルの $E_{0}$ の $\varphi_{0}$ 依存性を示 した。 $E_{0}$ は $\varphi_{0}$ に対してべき乗則を示し，その依存性はそれ ぞれ $\varphi_{0}{ }^{1.32}, \varphi_{0}{ }^{1.29}$ となり, 式 (4)の予測と比べて大きな值を取っ ている。これは低濃度領域において弾性に寄与しないルー プ構造などが形成していることを示唆している. ${ }^{14,17,23)}$ Figure 3 (b)に $E_{0}$ の $\varphi_{0} / N_{\mathrm{p}}$ 依存性を示した. 図中の点線は式 (4)の予 測值を示しており，実験值が点線に漸近する挙動を示した. マスターカーブからのズレは上記のループ構造の他に, 濃 度の増大に伴い架橋点の摇らぎが抑制されていることに起 因する. ${ }^{14,17)} こ の$ 結果から, 特に高い $\varphi_{0} / N_{\mathrm{p}}$ 領域では調製時の 弾性率 $E_{0}$ は $\left(\varphi_{0} / N_{\mathrm{p}}\right)^{1}$ でスケールされ, 式 (4) に示される古典 ゴム弾性理論に従うことがわかった。

\section{2 弾性率の $\varphi_{\mathrm{m}}$ 依存性について}

本章では調製状態のゲルを測定時の体積分率を固定し て, 膨潤・脱膨潤させた時の弾性率について議論をする. Figure 4 に 10 k, 20 k Tetra-PEG ゲルの弾性率の測定時濃度 $\left(\varphi_{\mathrm{m}}\right)$

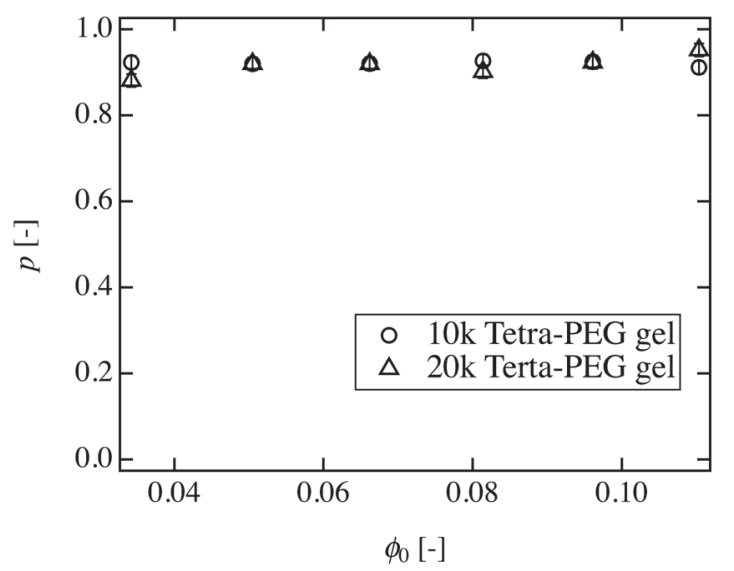

Fig. 1. $\varphi_{0}$-dependences of $p$ for the $10 \mathrm{k}$ and $20 \mathrm{k}$ Tetra-PEG gels. ${ }^{18)}$ Reproduced by permission of the Royal Society of Chemistry.

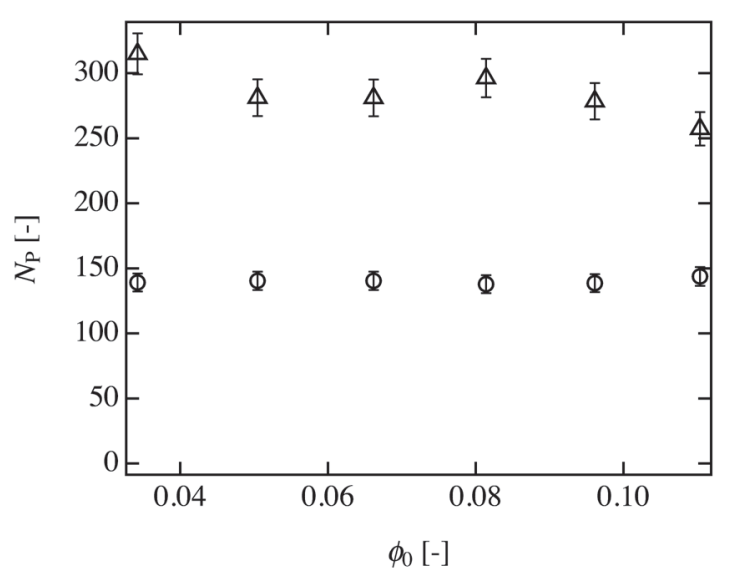

Fig. 2. $\varphi_{0}$-dependences of $N_{\mathrm{p}}$ for the $10 \mathrm{k}$ and $20 \mathrm{k}$ Tetra-PEG gels. Circles and triangles represent the $10 \mathrm{k}$ and $20 \mathrm{k}$ Tetra-PEG gels, respectively. ${ }^{18)}$ - Reproduced by permission of the Royal Society of Chemistry. 
依存性を示す。 $\bigcirc$, 及び $\triangle$ 印はそれぞれ $\varphi_{0}=0.034, \varphi_{0}=0.096$ のデータである。弾性率は $N, \varphi_{0}$ に依らず， $\varphi_{\mathrm{m}}$ に対してべキ 乗則を示し, $\varphi^{*}$ 付近 $\left(\varphi^{*}{ }_{10 \mathrm{k}}=0.062\right.$ 及び $\left.\varphi^{*}{ }_{20 \mathrm{k}}=0.035\right)$ でクロ スオーバーを示した。 $\varphi^{*}$ は，プレポリマー溶液の粘度測定 から固有粘度を求め, 剛体球近似を用いて算出した. ${ }^{17)} フ ィ ッ$ ティングラインの傾きは 0.33 (点線) と 0.57 (実線) となり, それぞれ式 $(8 \mathrm{a}, \mathrm{c}),(8 \mathrm{~b}, \mathrm{~d})$ の予測に良く一致した。このとき， 平衡膨潤実験から求めた $v$ の值 $(=0.59)$ を用いた (4.3 参照). この結果は Obukhov らの理論の有用性を示すと共に, ベキ 乗則のクロスオーバーが排除体積効果に依るものであるこ とを示唆している。

\section{3 平衡膨潤状態について}

本章ではゲルの平衡膨潤状態が調製時濃度にどのように依 存するかについて議論をする. Fig. 5, 6 は 10 k, 20 k Tetra-PEG ゲルの $\varphi_{\mathrm{s}}$ と $E_{\mathrm{s}}$ の $\varphi_{0}$ 依存性を示している。 $\varphi_{\mathrm{s}}, E_{\mathrm{s}}$ は $\varphi_{0}$ に対し てベキ乗則を示し， $\varphi^{*}$ 周辺でクロスオーバーを示した. $10 \mathrm{k}$ Tetra-PEG ゲルは $\varphi^{*}$ の前後で $\varphi_{\mathrm{S}} \sim \varphi_{0}{ }^{0.56}, \varphi_{0}{ }^{0.33}$ 及び $E_{\mathrm{S}} \sim \varphi_{0}{ }^{1.3}$, $\varphi_{0}^{0.76}$ のベキを示した. $20 \mathrm{k}$ Tetra-PEG ゲルは $\varphi^{*}$ 以上の領域で $\varphi_{\mathrm{S}} \sim \varphi_{0}^{0.53}$ 及び $E_{\mathrm{S}} \sim \varphi_{0}{ }^{1.2}$ のベキ乗則を示した。 このクロスオー バーは Obukhovらの理論予測に良く一致している。式 (10),

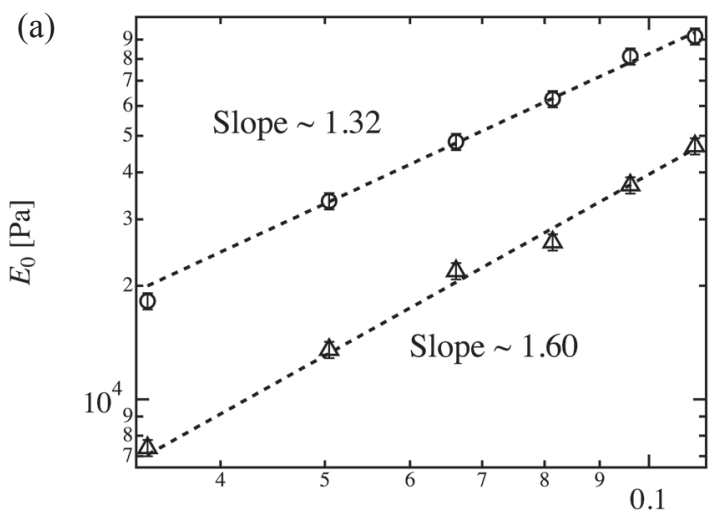

$\phi_{0}[-]$

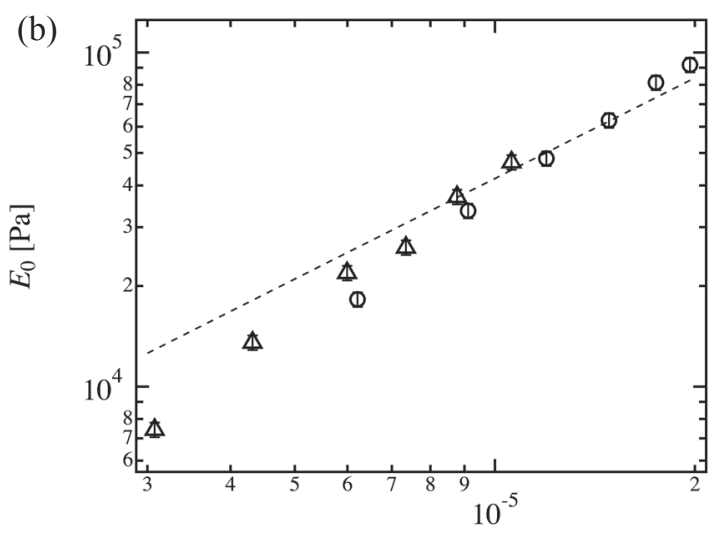

$\phi_{0} / N_{\mathrm{P}}[-]$

Fig. 3. (a) $\varphi_{0}$-dependences of $E_{0}$ for the $10 \mathrm{k}$ and $20 \mathrm{k}$ Tetra-PEG gels. Dashed lines represent the fitting lines. (b) $\varphi_{0} / N_{\mathrm{p}}$-dependences of $E_{0}$ for the $10 \mathrm{k}$ and $20 \mathrm{k}$ Tetra-PEG gels. Dashed line represents the prediction of eq. (4). Circles and triangles represent the $10 \mathrm{k}$ and $20 \mathrm{k}$ Tetra-PEG gels, respectively. ${ }^{18)}$ - Reproduced by permission of the Royal Society of Chemistry.
(11) を用いると, $v=0.59$ が得られた. この值は水溶液中の PEG の固有粘度 $[\eta]$ と分子量 $M$ の関係から $[\eta] \sim M^{3 v-1}$ を用い て, 得られた值 $(0.58)$ に非常に近く, 妥当な值であると考え られる. ${ }^{24)}$ 一般によく知られている $C^{*}$ 定理 ${ }^{20)}$ はこのクロス オーバーを予測出来ない． $C^{*}$ 定理では， $\varphi_{0}$ に依らず平衡膨 潤時において重なり合い濃度が最安定状態であると考えてい るためである。C*定理の破れは，弾性の自由エネルギーが $\varphi_{0}$ 依存性を明確に持っていることを示している.

Fig. 7 は 10 k, 20 k Tetra-PEG ゲルにおける $E_{\mathrm{s}}$ の $\varphi_{\mathrm{s}}$ 依存性を 示している。全てのデータは $\varphi_{0}, N$ に依らず傾き 2.3 のカー ブ上に載っており，この指数は， $v=0.59$ とした時の式 (12) の理論予測 $\left(E_{\mathrm{s}} \sim \varphi_{\mathrm{s}}^{2.3}\right)$ と良く一致している。この指数は, 良 溶媒で平衡膨潤させたゲルを用いた実験にて得られた指数 に非常に近く，式(12) は網目構造の詳細に依らず成り立っ

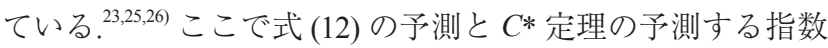
が等しいことは注意すべき点である。これまでに式 (12)の 実験的検証を以て， $C^{*}$ 定理の正当性を指示する論文もあっ たが, ${ }^{20,25,26)}$ 前述のように $C^{*}$ 定理は $E_{\mathrm{s}}$ 及び $\varphi_{\mathrm{s}}$ の $\varphi_{0}$ 依存性の クロスオーバーを説明できない. よって，これまでにも多 くの研究者により指摘されているように，C*定理は正しく ないことが本実験からも示された.9,10,27)

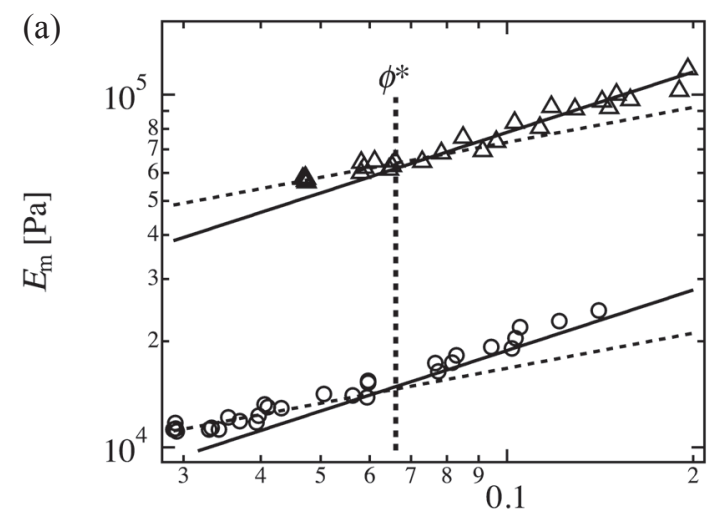

$\phi_{\mathrm{m}}[-]$

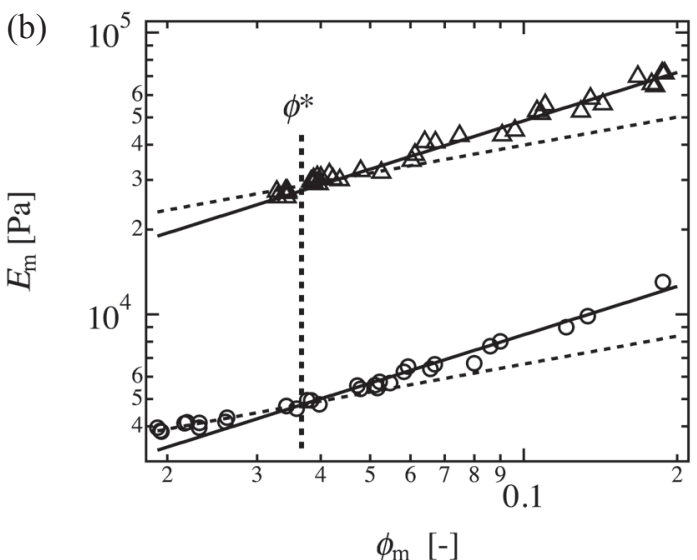

Fig. 4. The $\varphi_{\mathrm{m}}$-dependence of $E_{\mathrm{m}}$ for the $10 \mathrm{k}$ and $20 \mathrm{k}$ Tetra-PEG gels with different $\varphi_{0}$ s. ((a) The data for the $10 \mathrm{k}$ Tetra-PEG gels, (b) The data for the $20 \mathrm{k}$ Tetra-PEG gels) The circles and triangles denote the data of the gels with $\varphi_{0}=0.034$ and $\varphi_{0}=0.096$, respectively. The dashed and solid lines represent the relationships that $E_{\mathrm{m}} \sim \varphi_{\mathrm{m}}{ }^{0.33}$ and $\varphi_{\mathrm{m}}{ }^{0.57}$, respectively. 


\section{5. 結 論}

Tetra-PEG ゲルをモデル網目鎖として，高分子ゲルの調製 時及び測定時の濃度に対する弾性率の依存性, および平衡膨 潤状態の挙動を調べた。その結果, (1) Tetra-PEG ゲルの調製 時の弾性率 $\left(E_{0}\right)$ は古典的なゴム弾性理論に従うことがわかっ た. (2) 弾性率 $\left(E_{\mathrm{m}}\right)$ の測定時の高分子体積分率依存性は排除 体積効果によるクロスオーバーを示し, Obukhovらの理論を 用いてよく説明できた。 (3) 平衡膨潤状態の高分子体積分率 $\left(\varphi_{\mathrm{s}}\right)$ と弾性率 $\left(E_{\mathrm{s}}\right)$ は調製時濃度 $\left(\varphi_{0}\right)$ の影響を受け, 排除体積 効果を受けてクロスオーバーを示した。 この結果も Obukhov らの理論を用いてよく説明できた一方で, de Gennesの提唱 した $C^{*}$ 定理では説明が出来なかった. 以上のように, 構造 の明確な高分子ゲルを用いることにより, 高分子ゲルの膨 潤・収縮を予測するモデルを実験的に検証することに成功 した。

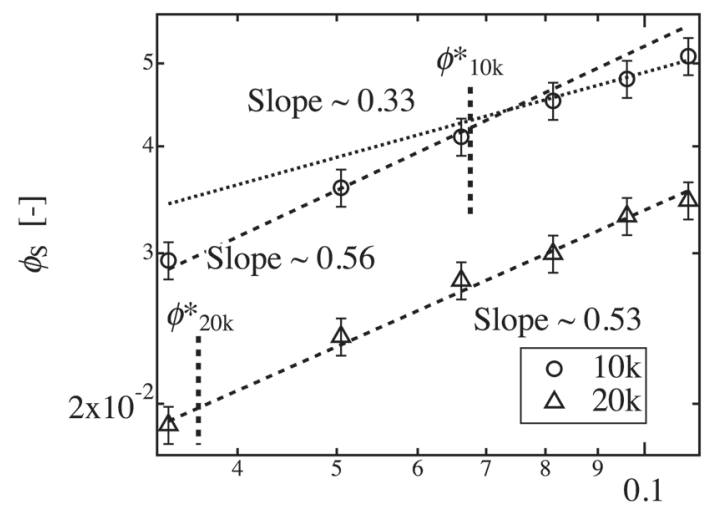

$\phi_{0}[-]$

Fig. 5. The $\varphi_{0}$-dependence of $\varphi_{\mathrm{s}}$ for the $10 \mathrm{k}$ and $20 \mathrm{k}$ Tetra-PEG gels. The circles and triangles denote the data of the $10 \mathrm{k}$ and $20 \mathrm{k}$ Tetra-PEG gels, respectively. ${ }^{18)}$ - Reproduced by permission of the Royal Society of Chemistry.

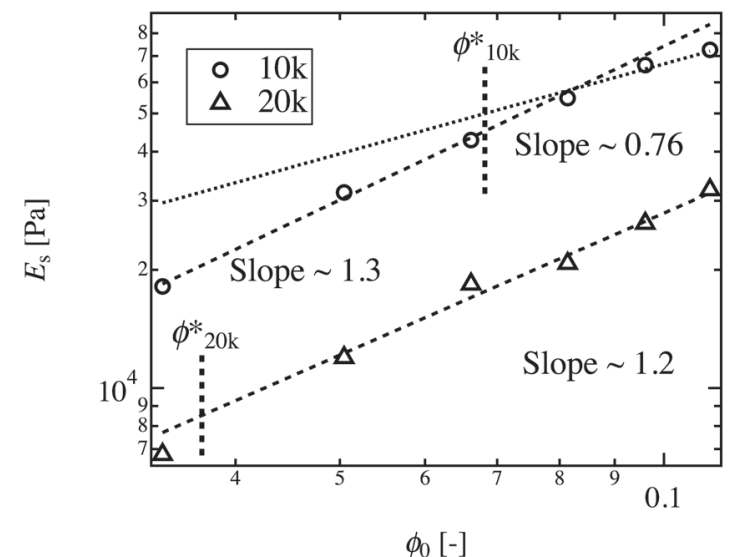

Fig. 6. The $\varphi_{0}$-dependence of $E_{\mathrm{S}}$ for the $10 \mathrm{k}$ and $20 \mathrm{k}$ Tetra-PEG gels. The circles and triangles denote the data of the $10 \mathrm{k}$ and $20 \mathrm{k}$ Tetra-PEG gels, respectively. ${ }^{18)}$ - Reproduced by permission of the Royal Society of Chemistry.

\section{謝辞}

本研究を遂行するに当たり，浦山健治教授（京都工芸繊維 大学）から頂いた多数の貴重なご助言に厚く感謝致します.

\section{REFERENCES}

1) Flory PJ, Principles of polymer chemistry, (Cornell University Press, Ithaca, 1953).

2) Flory PJ, Rehner J, J Chem Phys, 11 (11), 521-526 (1943).

3) Obukhov SP, Rubinstein M, Colby RH, Macromolecules, 27 (12), 3191-3198 (1994).

4) Ong CSM, Stein RS, Journal of Polymer Science: Polymer Physics Edition, 12 (8), 1599-1606 (1974).

5) Price C, Allen G, de Candia F, Kirkham MC, Subramaniam A, Polymer, 11 (9), 486-491 (1970).

6) Mark JE, Flory PJ, J Appl Phys, 37 (13), 4635-4639 (1966).

7) Hild G, Prog Polym Sci, 23 (6), 1019-1149 (1998).

8) Johnson RM, Mark JE, Macromolecules, 5 (1), 41-45 (1972).

9) Urayama K, Kawamura T, Kohjiya S, J Chem Phys, 105 (11), 4833-4840 (1996).

10) Urayama K, Kohjiya S, J Chem Phys, 104 (9), 3352-3359 (1996).

11) Sakai T, Reactive and Functional Polymers, 73 (7), 898-903 (2013).

12) Sakai $T$, Akagi $Y$, Matsunaga $T$, Kurakazu M, Chung U, Shibayama M, Macromol Rapid Comm, 31 (22), 1954-1959 (2010).

13) Sakai T, Matsunaga $T$, Yamamoto $Y$, Ito C, Yoshida R, Suzuki S, Sasaki N, Shibayama M, Chung U, Macromolecules, 41 (14), 5379-5384 (2008).

14) Akagi $Y$, Katashima $T$, Katsumoto $Y$, Fujii $K$, Matsunaga $T$, Chung U, Shibayama M, Sakai T, Macromolecules, 44 (14), 5817-5821 (2011).

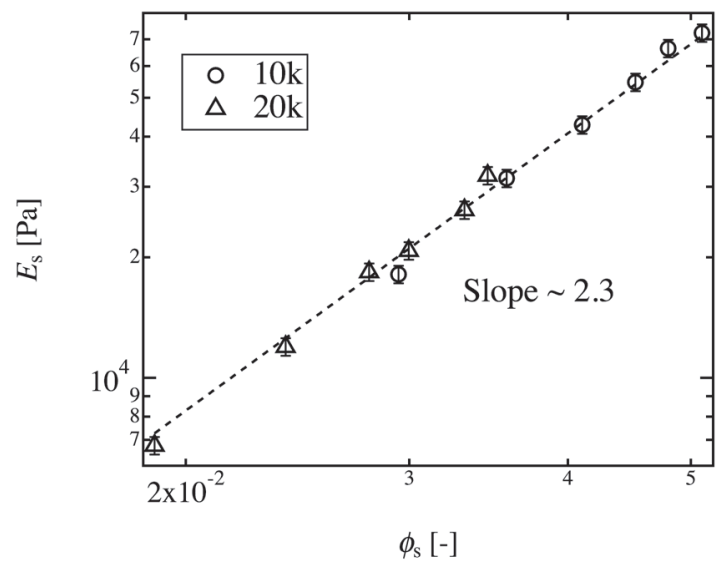

Fig. 7. The $\varphi_{\mathrm{s}}$-dependence of $E_{\mathrm{S}}$ for the $10 \mathrm{k}$ and $20 \mathrm{k}$ Tetra-PEG gels with different $\varphi_{0}$ s. The circles and triangles denote the data of the $10 \mathrm{k}$ and $20 \mathrm{k}$ Tetra-PEG gels, respectively. ${ }^{18)}$ - Reproduced by permission of the Royal Society of Chemistry. 
15) Lange F, Schwenke K, Kurakazu M, Akagi Y, Chung U, Lane M, Sommer JU, Sakai T, Saalwachter K, Macromolecules, 44 (24), 9666-9674 (2011).

16) Matsunaga $T$, Sakai $T$, Akagi $Y$, Chung U, Shibayama M, Macromolecules, 42 (4), 1344-1351 (2009).

17) Akagi Y, Gong JP, Chung U, Sakai T, Macromolecules, 46 (3), 1035-1040 (2013).

18) Sakai T, Kurakazu M, Akagi Y, Shibayama M, Chung U, Soft Matter, 8 (9), 2730-2736 (2012).

19) Panyukov SV, Zh Eksp Teor Fiz, 98, 668-680 (1990).

20) de Gennes PG, Scaling concepts in polymer physics, (Cornell University Press, Ithaca, N.Y., 1979).
21) Flory PJ, Rehner J, J Chem Phys, 11 (11), 512-520 (1943).

22) Miller DR, Macosko CW, Macromolecules, 9 (2), 206-211 (1976).

23) Vasiliev VG, Rogovina LZ, Slonimsky GL, Polymer, 26 (11), 1667-1676 (1985).

24) Kirinčič S, Klofutar C, Fluid Phase Equilibria, 155 (2), 311325 (1999).

25) Candau S, Peters A, Herz J, Polymer, 22 (11), 1504-1510 (1981).

26) Zrinyi M, Horkay F, Macromolecules, 17 (12), 2805-2811 (1984).

27) Kawamura T, Urayama K, Kohjiya S, Nihon Reoroji Gakkaishi, 25 (4), 195-196 (1997). 